\title{
A Perspective for Assembling SALP (Streptomyces Artificial Linear Plasmid): A Potential New Genetic Tool of Gene Manipulation System for Producing Bioactive Secondary Metabolites in Streptomyces
}

\section{Mingxuan $\mathrm{Xu}$ *}

Department of Neurology, Baylor College of Medicine, Houston, TX, USA

Streptomyces genus is a very important industrial bacterial and a major natural source (about $2 / 3$ ) of bio-active secondary metabolites including antibiotics used today [1].

Genetic systems for combinatorial biosynthesis of bioactive products including antibiotic have been developed in Streptomyces genus. Several shuttle vectors, including circular plasmid, cosmid, BAC (Bacterial Artificial Chromosome)/PAC (P1-derived Artificial Chromosome) between E. coli-Streptomyces have been used for manipulation of Streptomyces gene cluster for producing bioactive chemicals. Usually normal circular plasmids can carry only 1-20 kb DNA size. Cosmids are able to carry 37 to $52 \mathrm{~kb}$ of DNA, it was reported that cosmids have been successfully used for construction of Streptomyces genome libraries to clone biosynthetic gene clusters [2-7]. Nonetheless, most biosynthetic gene clusters for natural products are larger than the average capacity of common cosmid vectors, thus, vectors with large capacity such as $\mathrm{BAC}$ or PAC have been used to construct E. coli-Streptomyces artificial chromosomes for heterologous production of secondary metabolites [8-14]. The DNA fragments insertion loading capacity for BAC/PAC is from $100 \mathrm{~kb}$ up to $100-300 \mathrm{~kb}$ in E. coli cell, the large capacity of BAC/ $\mathrm{PAC}$ allows the gene manipulation of complete biosynthesis gene cluster of secondary metabolites in bacteria E. coli cell. However, E coli is not an ideal host for heterologous gene overexpression and production of Streptomyces biosynthesis gene cluster due to its lower genomic GC content compare to Streptomyces's. In addition, BAC capacity can be up to $100 \mathrm{~kb}$ and more, but the copy number usually is low. Therefore, a shutter capability for the vector to introduce BAC back to Streptomyces host is required for efficient production. Intergeneric conjugation is a major approach for manipulating DNA shuttered between Streptomyces and E. coli [11].

Different from most other eubacteria, the plasmids and chromosomes in Streptomyces species are usually linear [15,16], some Streptomyces species harbor multiple linear plasmids up to three [17]. The sizes of linear plasmids range are from $12 \mathrm{~kb}$ [18] to $1800 \mathrm{~kb}$ [6]. More and more linear plasmids in Streptomyces have been identified. Some of natural endogenous giant linear plasmids have been discovered carrying gene clusters for the production of secondary metabolites including antibiotics biosynthesis clusters [19-21].

In this editorial, the possibility for developing SALP: Streptomyces Artificial Linear Plasmid, a new genetic tool for gene manipulation system based on the backbone elements of linear plasmid in Streptomyces is discussed.

Streptomyces species harbor linear plasmids varied in number and size. Linear plasmids can interact with chromosome, genetic exchanges between chromosome and linear plasmids including some giant linear plasmids occur via recombination, transposition etc. $[16,21]$. Linear plasmids share some common functional mechanism with chromosome and are able to recruit chromosome encoded protein to perform functions such as replication as linear mode in Streptomyces [22]. The capacity of linear plasmid could be very big, up to $1.8 \mathrm{M}$, those endogenous linear plasmids are stable expressed In vivo, and a majority of them replicate as high copy number. A certain number of linear plasmids are capable of self-conjugative transfer. The mechanism of linear plasmid conjugation is different from that of circular plasmid, it was reported that in addition to classic tra gene which was identified as essential transfer gene for Streptomyces circular plasmid, more gene loci and/or elements are required for linear plasmid efficient conjugation transfer $[9,11,23-26]$. Genes involved in efficient transfer usually cotranscript in an operon cluster, a six co-transcribed genes including a tra gene encoding Tra-like DNA translocase has been identified for SLP2 which is a $50 \mathrm{~kb}$ endogenous linear plasmid in extensively-studied model strain: Streptomyce lividance $[24,25]$.

To construct an ideal shutter SALP vector, several essential factors should be taken into account: capacity for carrying large size DNA; replication in Streptomyces with high efficiency; efficient intergenetic conjugation transfer. Due to its natural characters, endogenous linear plasmid in Streptomyces is capable of serving as a potential source for constructing new genetic tools to manipulating bioactive secondary metabolites gene cluster. First of all, Streptomyces linear plasmids derived from Streptomyces and are able to replicate and express stably In vivo. Secondly, the capacity is big: endogenous giant linear plasmids whose size varied from hundreds to thousands $\mathrm{kb}$ have been isolated and characterized, some of them carry natural antibiotics synthesis gene cluster. Thirdly, some linear plasmids carry conjugation transfer operon that allows them efficiently transfer between different host species.

In summary, more and more linear plasmids in Streptomyces have been identified and characterized. Accumulated fundamental studies on linear plasmid reveal their functions and molecular mechanism. Those findings provide insights into molecular basis of essential elements required for genetic manipulation system.

\section{Acknowledgments}

I would like to thank Prof. Zhongjun Qin and Prof. Guoping Zhao who are experts in this field, for their support and suggestions.

\section{References}

1. Kieser T, Bibb MJ, Buttner MJ, Chater KF, Hopwood DA (2000) Practical Streptomyces Genetics. (2nd ed.), Norwich, England: John Innes Foundation.

2. Medema MH, Trefzer A, Kovalchuk A, van den Berg M, Müller U, et al. (2010)

*Corresponding author: Mingxuan Xu, Department of Neurology, Baylor College of Medicine, Houston, TX, USA, E-mail: xumingxuan@gmail.com

Received December 15, 2012; Accepted December 17, 2012; Published December 19, 2012

Citation: Mingxuan Xu (2013) A Perspective for Assembling SALP (Streptomyces Artificial Linear Plasmid): A Potential New Genetic Tool of Gene Manipulation System for Producing Bioactive Secondary Metabolites in Streptomyces. Biochem Anal Biochem 2:e132. doi:10.4172/2161-1009.1000e132

Copyright: ( 2013 Mingxuan Xu. This is an open-access article distributed unde the terms of the Creative Commons Attribution License, which permits unrestricted use, distribution, and reproduction in any medium, provided the original author and source are credited. 
Citation: Mingxuan Xu (2013) A Perspective for Assembling SALP (Streptomyces Artificial Linear Plasmid): A Potential New Genetic Tool of Gene Manipulation System for Producing Bioactive Secondary Metabolites in Streptomyces. Biochem Anal Biochem 2:e132. doi:10.4172/2161. 1009.1000e132

The sequence of a 1.8-mb bacterial linear plasmid reveals a rich evolutionary reservoir of secondary metabolic pathways. Genome Biol Evol 2: 212-224

3. Steffensky M, Mühlenweg A, Wang ZX, Li SM, Heide L (2000) Identification of the novobiocin biosynthetic gene cluster of Streptomyces spheroides NCIB 11891. Antimicrob Agents Chemother 44: 1214-1222

4. Pojer F, Li SM, Heide L (2002) Molecular cloning and sequence analysis of the clorobiocin biosynthetic gene cluster: new insights into the biosynthesis of aminocoumarin antibiotics. Microbiology 148: 3901-3911.

5. Cone MC, Yin X, Grochowski LL, Parker MR, Zabriskie TM (2003) The blasticidin $\mathrm{S}$ biosynthesis gene cluster from Streptomyces griseochromogenes: sequence analysis, organization, and initial characterization. Chembiochem 4 : 821-828.

6. Singh D, Seo MJ, Kwon HJ, Rajkarnikar A, Kim KR, et al. (2006) Genetic localization and heterologous expression of validamycin biosynthetic gene cluster isolated from Streptomyces hygroscopicus var. limoneus KCCM 11405 (IFO 12704). Gene 376: 13-23.

7. Kinashi H (2011) Giant linear plasmids in Streptomyces: a treasure trove of antibiotic biosynthetic clusters. J Antibiot (Tokyo) 64: 19-25.

8. Zhang R, Zeng A, Fang P, Qin Z (2008) Characterization of replication and conjugation of Streptomyces circular plasmids pFP1 and pFP11 and their ability to propagate in linear mode with artificially attached telomeres. Appl Environ Microbiol 74: 3368-3376.

9. Chen W, Qin Z (2011) Development of a gene cloning system in a fastgrowing and moderately thermophilic Streptomyces species and heterologous expression of Streptomyces antibiotic biosynthetic gene clusters. BMC Microbiol 11: 243

10. Tian Y, Jiang W, Zhao G, Qin Z (2009) In vivo conjugation-coupled recombinational cloning of a Streptomyces lividans chromosomal telomeric DNA using a linear plasmid. Biotechnol Lett 31:1253-1258.

11. Alexander DC, Rock J, He X, Brian P, Miao V, et al. (2010) Development of a genetic system for combinatorial biosynthesis of lipopeptides in Streptomyces fradiae and heterologous expression of the A54145 biosynthesis gene cluster. Appl Environ Microbiol 76: 6877-6887.

12. Phornphisutthimas $S$, Sudtachat N, Bunyoo $C$, Chotewutmontri P, Panijpan $B$, et al. (2010) Development of an intergeneric conjugal transfer system for rimocidin-producing Streptomyces rimosus. Lett Appl Microbiol 50: 530-536

13. Huiqun D, Xiaofeng C, Jianxin P, Huazhu H, Koji I, et al. (2010) Practica procedures for genetic manipulation systems for medermycin-producing Streptomyces sp. AM-7161. J Basic Microbiol 50: 299-301.
14. Xu M, Zhu Y, Zhang R, Shen M, Jiang $W$, et al. (2006) Characterization of the genetic components of Streptomyces lividans linear plasmid SLP2 for replication in circular and linear modes. J Bacteriol 188: 6851-6857.

15. Hirochika H, K Sakaguchi (1982) Analysis of linear plasmids isolated from Streptomyces: association of protein with the ends of the plasmid DNA Plasmid 7:59-65.

16. Omura S, Ikeda H, Malpartida F, Kieser HM, Hopwood DA (1986) Production of new hybrid antibiotics, mederrhodins $A$ and $B$, by a genetically engineered strain. Antimicrob Agents Chemother 29: 13-19.

17. Lin YS, Kieser HM, Hopwood DA, Chen CW (1993) Chromosomal DNA of Streptomyces ividans 66 is linear. Mol Microbiol 10: 923-933.

18. Kinashi H, Mori E, Hatani A, Nimi O (1994) Isolation and characterization of linear plasmids from lankacidin-producing Streptomyces species. J Antibiot (Tokyo) 47: 1447-1455

19. Wang J, Pettis GS (2010) The tra locus of streptomycete plasmid plJ101 mediates efficient transfer of a circular but not a linear version of the same replicon. Microbiology 156: 2723-2733.

20. Zhang R, Xia H, Guo P, Qin Z (2009) Variation in the replication loci of Streptomyces linear plasmids. FEMS Microbiol Lett 290: 209-216.

21. Yamamoto S, He Y, Arakawa K, Kinashi H (2008) Gamma-butyrolactonedependent expression of the Streptomyces antibiotic regulatory protein gene srrY plays a central role in the regulatory cascade leading to lankacidin and lankamycin production in Streptomyces rochei. J Bacteriol 190: 1308-1316.

22. Liu H, Jiang H, Haltli B, Kulowski K, Muszynska E, et al. (2009) Rapid cloning and heterologous expression of the meridamycin biosynthetic gene cluster using a versatile Escherichia coli-Streptomyces artificial chromosome vector pSBAC. J Nat Prod 72: 389-395.

23. Koberska M, Kopeck'y J, J Olsovska (2008) Sequence analysis and heterologous expression of the lincomycin biosynthetic cluster of the type strain Streptomyces lincolnensis ATCC25466. Folia Microbiologica 53: 395-401.

24. Alduina R, Gallo G (2012) Artificial chromosomes to explore and to exploit biosynthetic capabilities of actinomycetes. J Biomed Biotechnol 2012: 462049

25. Lee HH, Hsu CC, Lin YL, Chen CW (2011) Linear plasmids mobilize linear but not circular chromosomes in Streptomyces: support for the 'end first' model of conjugal transfer. Microbiology 157: 2556-2568.

26. Xu MX, Zhu YM, Shen MJ, Jiang WH, Zhao GP et al. (2006). Characterization of the essential gene components for conjugal transfer of Streptomyces lividans linear plasmid SLP2. Progress in Biochemistry and Biophysics. 33: 986-993.
Citation: Mingxuan Xu (2013) A Perspective for Assembling SALP (Streptomyces Artificial Linear Plasmid): A Potential New Genetic Tool of Gene Manipulation System for Producing Bioactive Secondary Metabolites in Streptomyces. Biochem Anal Biochem 2:e132. doi:10.4172/2161. 1009.1000e132 